\title{
An Overview on Control Concepts of Push-Belt CVT
}

\author{
Sameh Bdran, Samo Saifullah, and Ma Shuyuan
}

\begin{abstract}
This paper gives a general overview of push-belt CVT emphasizing on the concepts of ratio, slip and the rate of ratio change control. Accurate control of the CVT transmission is essential to achieve the intended fuel economy, ensure a good drivability and moreover maximize the efficiency of CVT.
\end{abstract}

Index Terms— Push-belt CVT, control, hydraulic.

\section{INTRODUCTION}

The continuously variable transmission (CVT) market is continuously increasing. In fact, the request for better energy efficiency and for $\mathrm{CO}_{2}$ and $\mathrm{NO}_{x}$ reduction, imposed by environmental considerations, pushes many researchers to find new technical solution to improve the emission performance of nowadays IC engine vehicles.

The continuously variable transmission, surely, represents one of the most promising solutions since it is able to provide an infinite number of gear ratios between two finite limits, thus enabling the IC engine to operate closer to its optimal efficiency line.

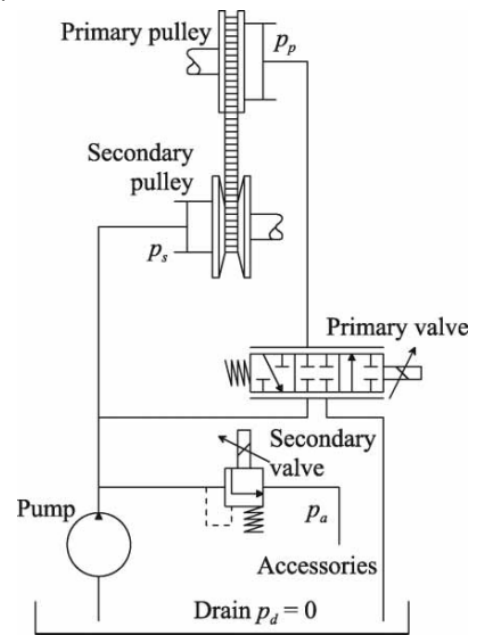

Fig. 1. Overview of push-belt CVT [2].

The CVT and its hydraulic actuation is shown in Fig. 1, the CVT consists of a variator including a V-belt, an actuation system. The variator forms the heart of the CVT which consists of a V-shaped metal belt composed of a thin $\mathrm{V}$-element and string, which mounted between two sets of conical sheaves, also called pulley. The belt runs on two pulleys, namely the primary pulley (driver) at the engine side and the secondary pulley (driven) at the wheel side. Each pulley is composed of one fixed conical sheave and second conical sheave movable in its axial direction. Varying the axial distance between the sheaves of each pulley leads to the

Manuscript received May 29, 2012; revised June 30, 2012.

The authors are with the Mechatronic Center of Mechanical Engineering, Beijing Institute of Technology, Beijing, China (e-mail: sameh_badran2008@yahoo.co) belt to move radially outward or inward, producing a continuous range of speed ratios safely, as shown in Fig. 2 $[1]$.

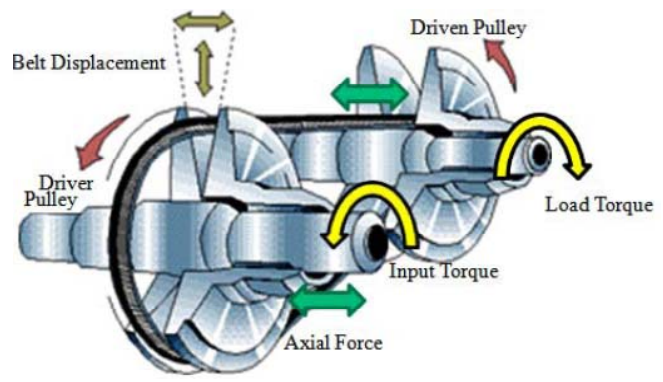

Fig. 2. Model of metal V-belt CVT.

By means of oil pressure in a hydraulic chamber the belt is clamped between the sheaves of each pulley that leads to the resulting tensile force in the string, combined with pushing force between the V-elements, allows the CVT to transmit power, the metal push-V belt construction is shown in Fig. 3.

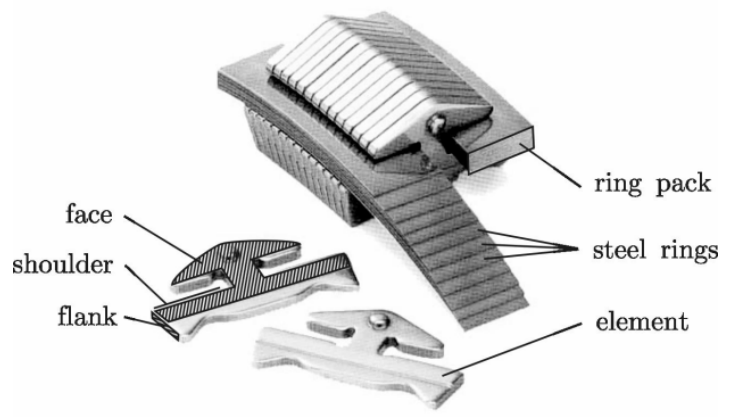

Fig. 3. Composition metal push-V belt.

The hydraulic actuation system is mainly used to implement the clamping force control and ratio control in the CVT operation. It pressurizes the fluid in the piston in each pulley to build the clamping force. Equally important, it controls fluid into and out of piston to achieve axial displacement of the pulleys, which in turn determines the CVT ratio.

The main focuses of this paper is on the ratio control, slip control, rate ratio control of push-belt CVT. The reminder of this paper is organized as follows. First, a working principle of push-belt CVT is mention in Section 2. Second, the control concepts of CVT are discussed in Section 3.

\section{Working Principle of PUSh-Belt CVT}

The push-belt type CVT utilizes friction to transmit power from the primary pulley to the secondary pulley. The working principle of variator is shown in Fig. 4, by adjusting the position of the pulleys the ratio of the variator change. The variator can cover any ratio between the two extremes, low and overdrive. The performance of push-belt type CVT depend on the way traction forces are generated and controlled. 


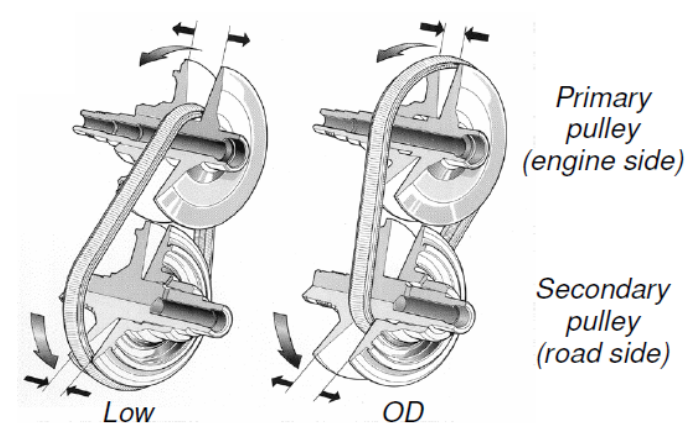

Fig. 4. Variator working principle.

The torque that is transmitted through the variator can be calculated using the force balance on a pulley [2], as shown in Fig. 5:

$$
T_{c v t, p, s}=\frac{2 \mu(v) F_{p, s} R_{p, s}}{\cos (\theta)}
$$

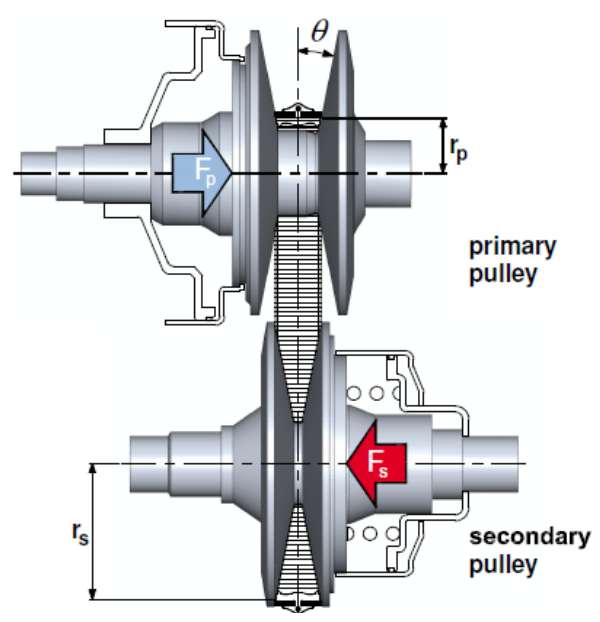

Fig. 5. Variator layout.

The relation between the traction coefficient $\mu$ and the slip $v$ is shown in Fig. 6. At first, for low slip values the traction coefficient increases with increasing slip, until a maximum value is reached. This region is called the microslip region. When the maximum value of the traction coefficient is reached, increasing slip will result in a slow decrease of the traction coefficient. This region is divided into two regions, the intermediate slip region and the macroslip region [2].

The intermediate slip region is defined as the region beyond the microslip region and below the macroslip region where damage to belt and/or sheaves can be expected after prolonged running [3].

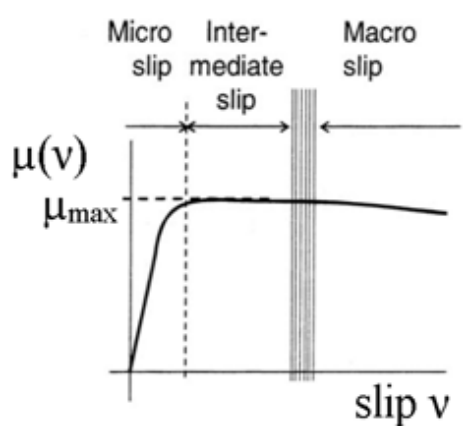

Fig. 6. Traction coefficient $\mu$ as a function of the relative slip $v$ [3].

\section{The Control Concepts of Push-Belt CVT}

The main goal of the CVT control is to achieve fast and accurate tracking of the desired ratio trajectory (speed ratio). An important sub-goal is to max efficiency and to minimize belt and pulley wear (slip control and rate of change ratio).

Hydraulic control system is responsible on the control of the clamping forces and the change of the CVT ratio. The clamping forces are generated on the belt to keep the slip level remains in the intermediate slip region such that torque can transmit and by controlling the rate of ratio change the desired output torque can be realized.

\section{A. Speed Ratio Control}

The desired ratio is usually chosen to improve the fuel efficacy and performance. The choice of ratio control influences the fuel economy and drivability and therefore will always be a compromise between the two.

Optimal Operation Line (OOL) tracking is the most fuel economical way to operate the driveline. However the power reserve is very low in most cases, therefore the drivability is influenced in a negative way [4]. A modified CVT ratio map is proposed to improve the engine-CVT overall system efficiency by considering the CVT loss (hydraulic loss and mechanical loss). The modified CVT ratio map is constructed with respect to demand vehicle power and present vehicle speed based on the steady state CVT loss [5].

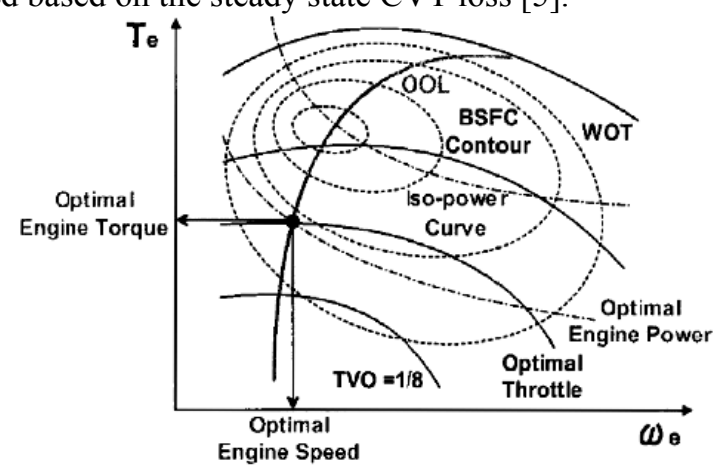

Fig. 6. Engine map with iso-power curve [4].

The CVT ratio controller in fact controls the primary and secondary pressure. When controlling the speed ratio at steady state, on one hand, the clamping force need to be high enough to prevent the damage by the slip, on the other hand a certain ratio of clamping forces has be achieved, that do called $\xi$ - ratio (ratio of clamping forces between driving and driven pulley) in order to sustain a certain speed ratio of the variator. $\xi$ is the most important non- linearity ratio of clamping forces between driving and driven pulley for steady state operation [6].

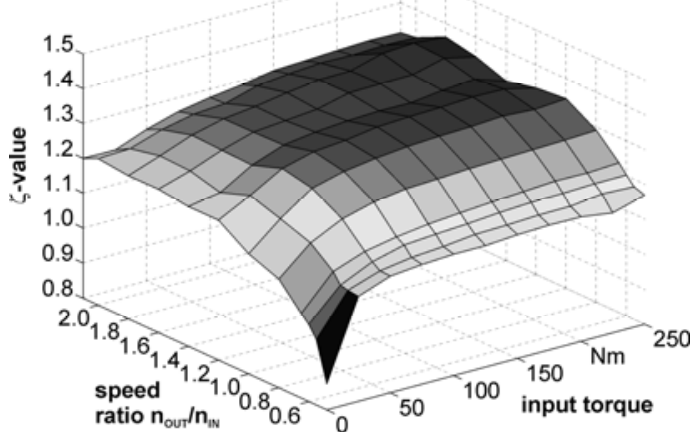

Fig. 7. $\xi$-map gathered and used by the speed ratio controller [6]. 
The total ratio controller guarantees that one clamping pressure setpoint is minimal, avoiding belt slip, while the other is raised above the minimum level to enable shifting. The controller consists of an anti-windup PID feedback part with linearizing weighting and a setpoint feedforward. Physical constraints on the system, especially with respect to the hydraulic pressures, are accounted for using a feedforward part to eliminate their undesired effects on the ratio [7].

\section{B. Slip Control}

In slip control, the clamping forces are actively controlled to maximize the efficiency of the CVT. This achieve by maintaining an amount of slip, where the traction coefficient near its maximum. This means that slip is controlled in the transition area of the micro and macroslip regions (intermediate slip region). An increase in the torque level will lead to an increase in belt slip, but by adjusting the clamping force to keep the slip in the optimized value, and meanwhile the slip will not reach destructive levels and therefore damage can be avoided. The most important requirement of the slip controller is that it has the ability to attenuate the load disturbance caused by torque peaks in the driveline [2].

Slip $v$ is determined by comparing the geometrical ratio with the speed ratio of the variator, defined as:

$$
\begin{gathered}
v=1-\frac{r_{s}}{r_{g}} \\
r_{g}=\frac{R p}{R_{s}} \\
r_{s}=\frac{\omega_{s}}{\omega_{p}}
\end{gathered}
$$

where $\omega_{\mathrm{p}} \omega \mathrm{s}$ are the angular speed for respectively the primary and the secondary pulley. The slip dynamics can be derived using (2) and (3), resulting in:

$$
\begin{gathered}
\dot{v}=-\frac{\dot{r}_{s}}{r_{g}} \\
\dot{r}_{s}=\frac{\dot{\omega}_{s} \omega_{p}-\omega_{s} \dot{\omega}_{p}}{\omega_{p}^{2}}
\end{gathered}
$$

The dynamics of the CVT can be described by:

$$
\begin{aligned}
& \dot{\omega}_{p}=\frac{T_{e}-T_{p}}{j_{e}} \\
& \dot{\omega}_{s}=\frac{T_{s}-T_{d}}{j_{s}}
\end{aligned}
$$

Combining (1)-(8) results in the following expression for the slip dynamics:

$$
\begin{aligned}
& \dot{v}=\frac{1}{\omega_{p}}\left(-\frac{2 F_{s} R_{s} \mu(v)}{\cos (\theta) j_{s} r_{g}}+\frac{T_{d}}{j_{s} r_{g}}\right)+ \\
& \frac{(1-v)}{\omega_{p}}\left(-\frac{2 F_{s} R_{s} r_{g} \mu(v)}{\cos (\theta) j_{e}}+\frac{T_{e}}{j_{e}}\right)
\end{aligned}
$$

where $j_{e}$ is the engine inertia, $j_{d}$ is the driveline inertia, $T_{e}$ is the engine torque and $T_{d}$ is the driveline torque.

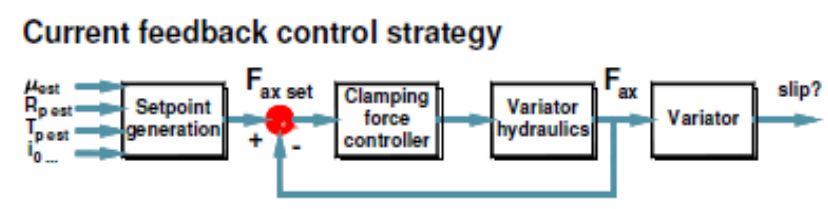

\section{New feedback control strategy}

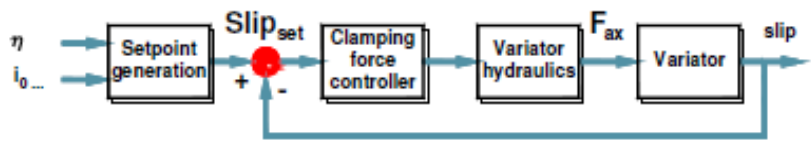

Fig. 9. The slip control strategy.

As shown in Fig. 9, the system uses the slip between the belt and pulley as the control parameter to adjust the secondary piston pressure based on the slip error. For the current control strategy, measurement of $F_{a x}$ is necessary, so this requires secondary pressure measurement. For slip control instead of secondary pressure measurement, measurement of variator slip is necessary.

The CVT slip control technique allows for best possible transmission efficiency, combined with improved robustness for slip damage. A Linear Quadratic Gaussian (LQG) controller is designed for the CVT slip control, as well as a Proportional Integral (PI) controller for CVT ratio control $[8]$.

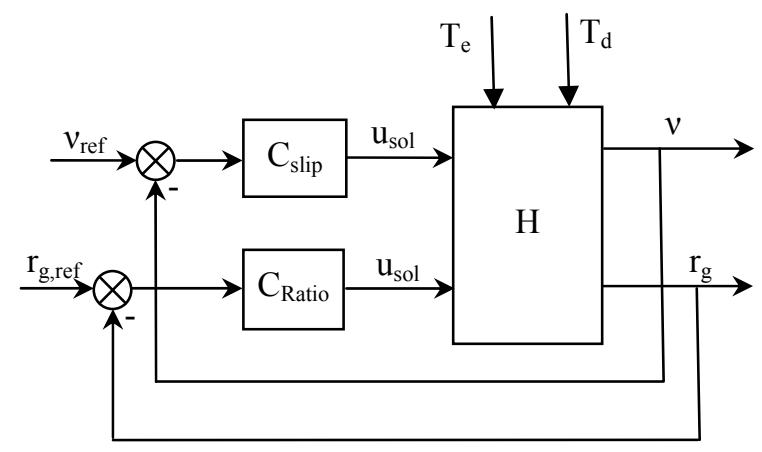

Fig. 10. Block diagram represent control strategy [8].

\section{Rate of Ratio Change Control}

During the transient operating condition of the CVT, for example when raising the engine speed in order to get more power for vehicle acceleration, it is favorable to control the rate of ratio change.

Fig. 7 show a simplified model, which usually used to describe the characteristic effect within the CVT drive train.

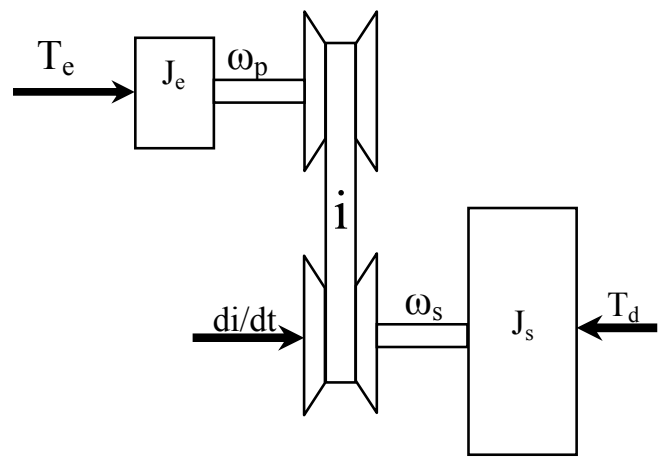

Fig. 10. Model of a CVT drive train [5]. 
Any change in speed ratio of the CVT predominantly leads to an acceleration or deceleration of the rotational mass Je (due to the relative low moment of inertia at the engine side compared to inertia at the wheel side Js) and therefore leads to change in engine speed. Thus available power at the wheel is lowered or raised according to the power needed for changing engine speed, the vehicle might even react converse to the driver command when the change in engine speed (respectively change of speed ratio at the CVT) happens too quickly. In extreme circumstances the vehicle would slow down in the first moment even when kick down in the first moment when kick down detent is being engaged. Therefore the possibility of controlling the rate of speed change $d i / d t$ is getting essential [5]. In a CVT drive train it is necessary to control as well quasi-stationary conditions (speed and speed ratio) as well as the transient behavior of the variator $(d i / d t)$.

\section{CONCLUSION}

Review on control strategy for push-belt continuously variable transmissions (CVT) has been discussed; the literature reviewed suggested that there is considerable disparity in the type of CVT models that have been used for control development. A continuously variable transmission is a promising automotive transmission technology that can provide higher fuel economy, reduced emissions, and better vehicle performance. Further, new research should be investigated in the context of CVT design and configuration.

\section{REFERENCES}

[1] M. D. Rienks, "Control and Identification of a Continuously Variable Transmission. Master thesis," Eindhoven 1995.

[2] R. J. Pulles. B. Bonsen, M. Steinbuch, and P. A. Veenhuizen, "Slip Controller Design and Implementation in a Continuously Variable Transmission," American Control Conference. 2005.

[3] P. A. Veenhuizen. B. Bonsen, T. W. G. L. Klaassen, K. G. O. van deMeerakker, H. Nijmeijer, and F. E. Veldpaus, "Simulated Behaviour of a Vehicle with V-belt Geared Neutral Transmission with variator slip control," IMechE 2005.

[4] N. Cholis, S. Ariyono, and A. A. Kadir, "A Review on Control Strategy for Electro-mechanical Rubber Belt Continuously Variable Transmissions (CVT)," National Conference in Mechanical Engineering Research and Postgraduate Studies (2nd NCMER 2010) 3-4 December 2010. Faculty of Mechanical Engineering, UMP Pekan, Kuantan, Pahang, Malaysia; pp. 804-813.

[5] W. Ryu and H. Kim, "CVT Ratio Control with Consideration of CVT System Loss," International Journal of Automotive Technology, vol. 9, no. 4, pp. 459-465, 2008.

[6] R. Mölle, "Control and Operating Behavior of Continuously Variable Chain Transmissions," SAE International Continuously Variable and Hybrid Transmission Congress, September 2004.

[7] M. Pesgens, B. Vroemen, B. Stouten, F. Veldpaus, and M. Steinbuch, "Control of a Hydraulically Actuated Continuously Variable Transmission," Vehicle System Dynamics, May 2006, vol. 44, no. 5, pp. 387-406.

[8] S. W. H. Simons, "Shift Dynamics Modelling for Optimization of Variator Slip Control in a Continuously Variable Transmission," Master thesis Eindhoven, 3rd July 2006. 